simpósio e intitulado "The chemistry and applications of metal complexes", o qual incluirá uma seleção dos artigos mais relevantes apresentados no âmbito deste congresso.

A presente edição do ISMEC (ISMEC2012), foi organizada pelo Instituto Superior Técnico da Universidade Técnica de Lisboa, em cooperação com a Sociedade Portuguesa de Química, tendo como Presidente da Comissão Organizadora a Prof. Maria Amélia Santos. O Comité Científico Internacional (CCI) do ISMEC2012 foi incumbido de selecionar o recipiente

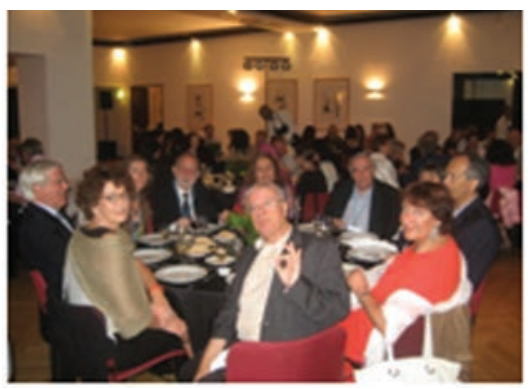

Jantar social (CCB) do Prémio Pulidori ( $5^{\text {th }}$ Edition), de entre 30 concorrentes, jovens investigadores participante no ISMEC2012 e autores de um artigo original publicado no período 2010-2012. O premiado deste ano foi Jorge González García, da Universidade de Valencia, com um artigo intitulado "Kinetics of $\mathrm{Zn}^{2+}$ complexation by a ditopic phenanthroline-azamacrocyclic scorpiand-like receptor", Chem. Commun. 2012, 48, 1994-1996. Um resumo alargado deste trabalho será também publicado na revista "La Chimica e L'industria", o jornal oficial da Sociedade Italiana de Química.

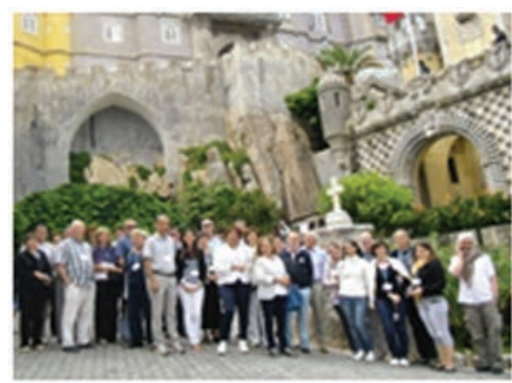

Visita a Sintra (grupo parcial)
A próxima Edição do ISMEC (ISMEC2013) realizar-se-á em Burgos (Espanha), em junho de 2013. O ISMEC2012 contou com o apoio institucional do IST, SPQ, CQE, FCG, a colaboração das empresas CGD, BPI, HOVIONE, ILC, TAP, Labor Spirit, Cruz-Porto, Hotel Açores e ainda dos departamentos de turismo das CM Lisboa e CM Sintra.

Maria Amélia Santos

(masantos@ist.utl.pt)

Presidente da Comissão Organizadora do ISMEC2012

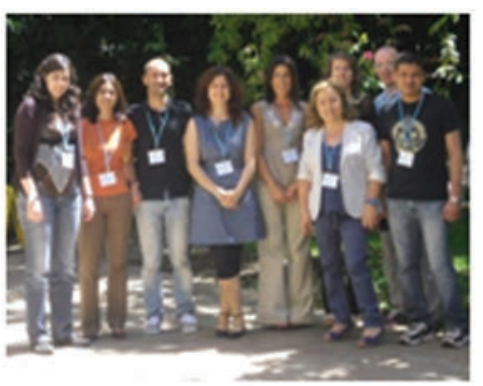

Comissão Organizadora

\title{
Simpósio de Homenagem ao Prof. Doutor Fernando Ramôa Ribeiro
}

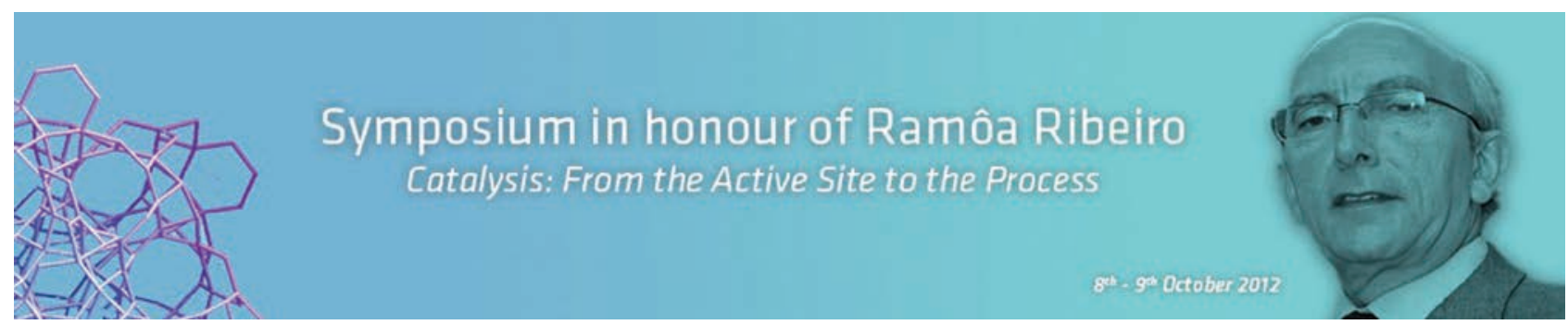

Decorreu, nos passados dias 8 e 9 de outubro, no Salão Nobre do Instituto Superior Técnico, o Simpósio de Homenagem ao Prof. Fernando Ramôa Ribeiro, subordinado ao tema "From the Active Site to the Process", um evento que teve o apoio da Sociedade Portuguesa de Química.

Fernando Ramôa Ribeiro, falecido em 29 de agosto de 2011, dedicou toda a sua vida científica à catálise, e em particular à catálise por zeólitos, domínio em que criou um grupo de investigação dinâmico, com uma elevada produtividade, quer a nível de formação de recursos humanos, em particular ao nível de doutoramentos, quer ao nível de publicações e de organização de encontros internacionais. Foi este gru- po de investigadores que decidiu organizar este Simpósio como forma de homenagear a memória deste Professor e Cientista recentemente falecido.

A atividade científica de Fernando Ramôa Ribeiro deu origem a uma vasta rede de contactos que, de certa forma, se reuniu neste simpósio em sua memória. A sessão de abertura contou com a presença, entre outras personalidades, do Ministro da Educação e Ciência, do Presidente do Conselho Geral e do Reitor da UTL, e do Presidente do IST que, para além da representação institucional, trouxeram os seus testemunhos do relacionamento com o Prof. Ramôa Ribeiro ao longo da sua carreira na área do Ensino Superior e da Ciência em Portugal. A ses- são contou ainda com a presença do Embaixador de França em Portugal, num reconhecimento ao trabalho desenvolvido por Ramôa Ribeiro em prol da colaboração científica e académica entre Portugal e França.

No plano científico, os trabalhos dividiram-se entre um conjunto de comunicações por destacados membros da comunidade científica ligada à catálise a nível Europeu e de Portugal, e um conjunto de apresentações ligadas a empresas da área da química que em Portugal e em França colaboraram com o Prof. Ramôa Ribeiro e a sua equipa.

As apresentações científicas contaram com personalidades como Michel 
Guisnet, orientador do doutoramento do Prof. Ramôa Ribeiro, Michel Che (Universidade Pierre et Marie Curie), Johan Martens (Universidade Católica de Louvain), Jean-Pierre Gilcon (Universidade de Caen) e os nossos colegas José Luís Figueiredo (FEUP), Mariette Pereira (Universidade de Coimbra) e Armando Pombeiro (IST/ UTL) e cobriram temas desde a síntese e caracterização de novos materiais até às aplicações em processos industriais, de acordo com o tema geral do Simpósio.

Entre as empresas participantes, destacam-se empresas como a GALP Energia, a CUF e o Instituto Francês dos Petróleos e a Petrobras. Nas comunicações dos representantes destas empresas ficou bem patente a necessidade do desenvolvimento da colaboração entre a academia e o tecido Industrial, sempre incentivado por Ramôa Ribeiro, e que deu origem

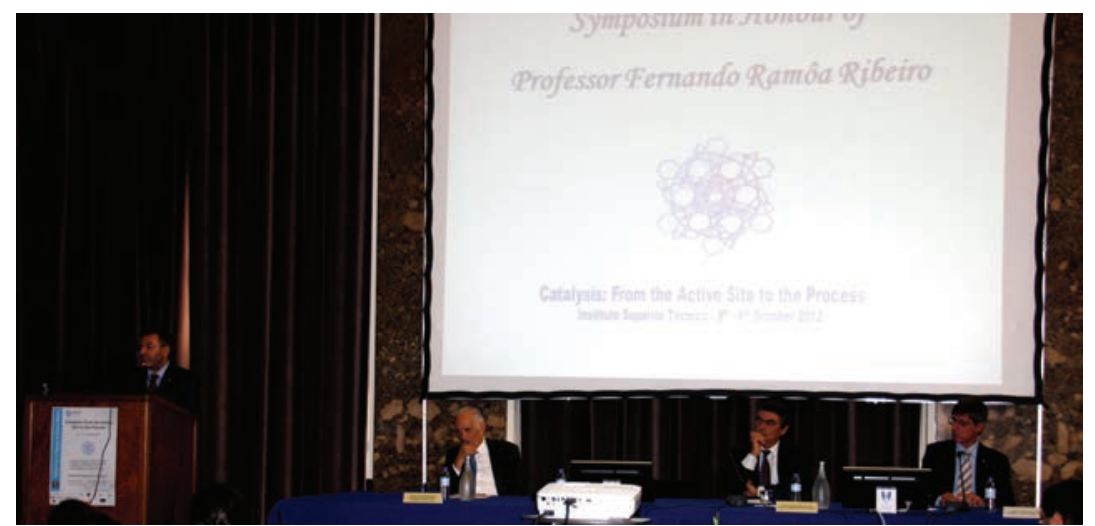

Intervenção do Ministro da Educação e Ciência na cerimónia de abertura do simpósio

recentemente à criação, pela GALP Energia, na refinaria de Sines, de um polo de investigação, precisamente dedicado ao Prof. Ramôa Ribeiro.

Os trabalhos contaram ainda com a apresentação de cerca de meia centena de posters originários de grupos de investigação de vários países, com particular incidência para os jovens investigadores que, de alguma forma, estiveram ligados aos trabalhos de investigação do homenageado.

Mais informações sobre o simpósio encontram-se disponíveis em: http://scrr.ist.utl.pt.

Francisco Lemos

(francisco.lemos@ist.utl.pt) Comissão Organizadora

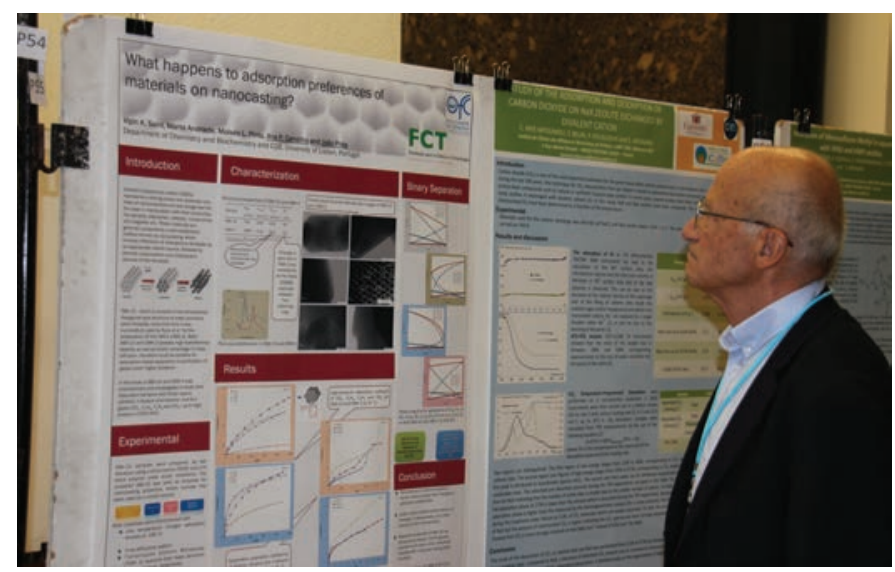

Jacques Védrine, um dos colaboradores de longa data de Ramôa Ribeiro, numa sessão de posters do simpósio

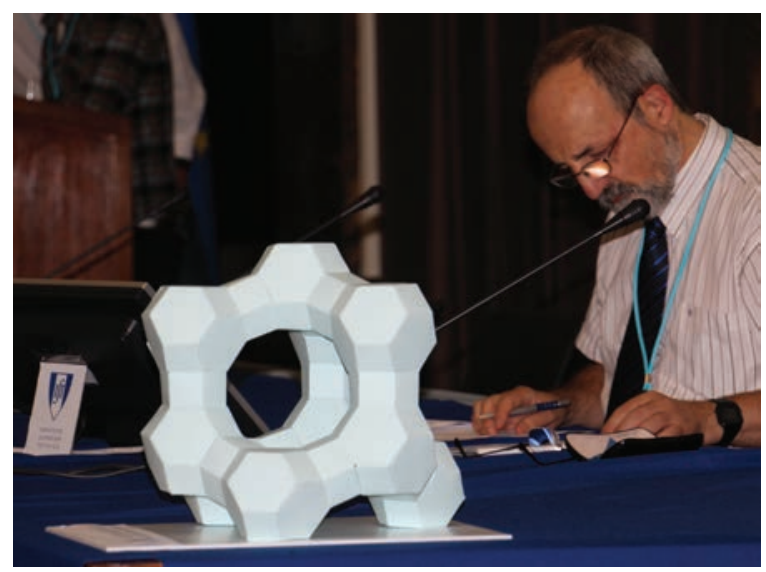

Esquema de uma estrutura de um zeólito em primeiro plano na mesa do simpósio e Vicente Córtez que se prepara para moderar uma das sessões

\section{$3^{\text {मо }}$ ITQB PhD StUdents' MeEting}

O $3^{\text {rd }}$ ITQB PhD Students' Meeting decorreu, de 10 a 12 de outubro de 2012 , no Instituto de Tecnologia Química e Biológica da Universidade Nova de Lisboa (ITQB-UNL), um evento apoiado pela Sociedade Portuguesa de Química. Organizado pelos estudantes de doutoramento do ITQB, este encontro anual pretende ser um palco onde, num ambiente descontraído, mas profissional, os alunos mostram e discutem os seus trabalhos com os seus pares. Nesta edição, foram apresentados 45 trabalhos (23 apresentações orais e 22 apresentações em poster), abrangendo áreas como a Química, Ciências Biológicas e Biotecnologias. Todos os alunos viram o seu trabalho ser discutido de forma bastante entusiástica pelo auditório, o que enriquece e motiva ainda mais o jovem cientista.

O encontro esteve aberto a toda a comunidade científica (entrada livre), tendo sido registadas 243 inscrições entre estudantes, investigadores, professores e oradores convidados.

Este ano tivemos o prazer de ouvir o Doutor Francisco Dionísio (FCUL) e a Doutora Luísa Figueiredo (IMM-FMUL) falarem sobre "Genetic conflicts" e "Chromatin dynamics in African Trypanosoma", respetivamente, mostrando a boa investigação em Ciências da Vida que se faz em Portugal. Numa vertente mais aplicada, o Doutor Arsénio Fialho (IST) falou-nos 